\title{
Empirical Analysis on the Correlation Between Shanghai Composite Index and Major Stock Index
}

\author{
Liu Jialing \\ School of Economics, Shanghai University, Shanghai, China
}

\section{Email address:}

Liuvicky0210@126.com

\section{To cite this article:}

Liu Jialing. Empirical Analysis on the Correlation Between Shanghai Composite Index and Major Stock Index. Science Innovation. Vol. 5, No. 5, 2017, pp. 318-324. doi: 10.11648/j.si.20170505.24

Received: July 6, 2017; Accepted: July 20, 2017; Published: August 16, 2017

\begin{abstract}
With the development of economic globalization and financial liberalization, the linkage between the world's economies has been strengthened, and the linkage between financial markets has become more and more obvious. In this paper, Shanghai (securities) composite index, Shenzhen composite index, Hang Seng Index, Dow Jones Industrial Average and Nikkei 225 Index are used as samples from January 4, 2006 to April 28, 2016, and the error correction model and impulse response were used. The results show that there is a balanced relationship between Shanghai Composite Index and the Shenzhen Component Index, Hang Seng Index, Nikkei 225 Index and Dow Jones Industrial Average, and Shanghai Composite Index did Granger Cause Shenzhen Composite Index and Hang Seng Index, but did not Granger cause Dow Jones Industrial Average and Nikkei 225 index, which indicates that the Shanghai Composite Index has less impact on Dow Jones Industrial Average and Nikkei 225 index. China's financial deepening and reform has a long way to go.
\end{abstract}

Keywords: Stock Market Correlation, Error Correction Model, Impulse Response

\section{上证综指与主要股票指数的联动性实证研究}

刘家玲

经济学院, 上海大学, 上海, 中国

邮箱

Liuvicky0210@126.com

摘要：随着经济全球化和金融自由化的发展，世界各经济体间的联系不断加强，金融市场之间的联动性愈加明显。本 文以2006年1月4日至2016年4月28日的上海综指、深圳成指、恒生指数、道琼斯工业指数、日经225指数为样本，运用 误差修正模型和脉冲响应对上证综指与所选样本股票市场之间的关系进行了实证研究，研究结果表明：上证综指与深 证成指、恒生指数、日经225指数以及道琼斯工业指数之间存在均衡关系, 且上证综指是深圳成指和恒生指数的Granger 原因, 但不是日经 225 指数和道琼斯工业指数的Granger原因, 表明上证综指对日经 225 指数和道琼斯工业指数的影响较 小。中国的金融深化与改革任重道远。

关键词: 股市联动, 误差修正模型, 脉冲响应 


\section{1. 引言}

经济全球化和金融自由化快速发展，世界各国之间的联 系更加紧密, 增强了全球经济、金融市场间的相互联系和依 赖性，全球金融市场之间的价格协同运动使一个地区的资本 市场发生局部性的波动, 并迅速传染到其他市场, 造成全球 的金融危机，2008年的全球金融危机就是一个事例。

随着我国QFII、QDII的引入和规模的不断扩大, 融资 融券业务以及股指期货业务的推出和发展, 金融领域的不 断深化改革与创新, 中国与其他国家的和地区的金融市场 之间的联系也越来越密切。中国股市与世界股市间存在" 同涨同跌"的长期均衡关系, 且中国股票市场逐渐从内生 性向外生性转变, 转变呈现出越来越强的趋势。2015年发 生的股市和汇市波动, 将市场的高度联动性和中国金融监 管框架的脆弱性暴露无遗。国际股票市场之间存在很强的 依赖性，任何市场所产生的信息对其他跨境股票市场来说 都是非常重要的, 不管股票市场资本化程度如何 [1]。对此 我国“十三五”规划提出, 中国应加强金融宏观审慎管理制 度建设, 改革并完善适应现代金融市场发展的金融监管框 架, 有效防范系统性、区域性金融风险。研究各个股票市 场指数之间的联系, 不仅有助于个人和机构投资者在股票 市场上对资产进行有效配置和风险管理, 同时对于加强宏 观审慎管理和防范金融系统风险均具有现实意义。

\section{2. 文献综述}

随着经济一体化的迅速发展, 证券市场也逐渐呈现趋 同的现象。一国股票市场是否与世界主要股票市场具有一 定的关联性, 也成为其成熟程度的标志。因此, 广大学者 和金融界越来越关注股票指数间联动关系。

2002年之前, 中国的股票指数变动与国际市场可以用 “绝缘”来形容。俞世典、陈守东等[2], 以1998年9月至2000 年10月的美国道琼斯指数和纳斯达克指数、香港恒生指数、 日经指数 225 与上证综指为研究样本, 运用协整检验分析、 误差修正模型、Granger因果检验等方法, 发现外国的股 票对上证综指有微弱的Granger因果关系, 可以忽略不计, 且中国的股票市场不是外国的股票市场变动的Granger因 果。陈守东和韩广哲等[3]以1992年11月-2002年7月的数据 为样本, 对中国沪深两市的股票指数和世界主要股市之间 的关系进行了实证研究, 指出各指数之间的收益率短期波 动并不相同, 且中国沪深两市的股票指数和其他股市指数 之间不存在协整关系, 得出我国股市和其他股市绝缘的结 论。韩非和肖辉 [4]研究中美股票市场的联动性研究表明中 国股市收盘对美国股市的开盘有影响但是影响很弱, 美国 股市收盘对中国股市开盘没有影响。倪振州和吉余锋 [5] 利用GARCH-M模型分析了次贷危机前后中美股市波动的 溢出效应, 结果表明次贷危机发生前中美股市波动不存在 溢出效应, 次贷危机后美国股市对中国股市的波动存在单 向溢出效应。刘婉婷、朱羽[6]以2000年至2008年之间的中、 美、英、日四个国家股票市场指数为样本, 利用 $V a R$ 模型 研究表明我国市场在2006年以后虽然仍旧有自己的独特 走势, 但已经开始与国际市场有了初步接轨。陈漓高、吴 鹏飞等[7]以1991年至2005年中日等10个亚洲地区以及美
国的股票指数为研究样本, 发现美国证券市场信息对亚洲 新兴市场未来的短期变动趋势有一定的预测性, 日本与亚 洲新型证券市场相关性较高, 但是中国的证券市场仍具有 较强的外生性。秦伟广与杨瑞成[8]研究了2002年至2009 年的中国股市与其他主要股市的每日收盘数据, 运用相关 性与协整检验和Granger因果关系检验等方法, 发现我国 市场日趋成熟, 逐渐与国际股票市场接轨。胡秋灵和刘伟 [9]研究结果表明在次贷危机影响下标普500指数日收益率 的前一期值对上证指数当日收益率有显著正向影响, 两指 数具有有一定的联动性。张兵、范致镇和李心丹 $[10]$ 研究 了2001年至2009年期间的中美股票指数, 采用Johansen协 整检验、多元GARCH-DCC模型等方法, 研究发现中国股 市与美国股市走势相对独立, 两者不存在长期的均衡关系, 但是中国股市受美国股市波动溢出的影响程度越来越大。 王一帆等[11]以2006年至2011年3月22日的上证指数和标 准普尔指数为样本, 利用协整检验和Granger因果关系检 验等方法, 研究我国QDII实施后到后金融时代时期这段时 间内中美股市之间的关系, 结果表明QDII实施后中美股市 间存在长期稳定均衡关系, 而且在金融危机后美国股市对 中国股市具有单向影响关系。裴延华、余万林 [12]以对 2013 年7月2日至2016年4月15日沪、港、美三个股票市场进行 实证分析, “沪港通”开通前, 上证综指波动几乎不受美股 和港股市场的影响，美市和港市与沪市没有联动性; “沪 港通”开通后，港股市场和美股市场对沪股市场的影响显 著增强。王杰、王帅[13]以中美股票市场为研究对象, 利 用基于VaR模型的Johansen协整检验和Granger因果检验 方法, 研究分析表明虽然中美股市二者间存在稳定的均衡 关系, 有显著的动态相关性, 但相关程度并不很高, 在绝 大部分时间, 两者是正相关关系, 少数时间出现负相关。 郑德珵等[14]采用1991年至2011年境内外主要股市数据, 通过DCC-MGARCH模型, 论证了主要股市市场之间联动 性增强, 相互之间冲击效果增大, 传导的速度越来越快, 随着股市间资金联动性的不断增加, 波动幅度也随之扩大。 李岸等[15]选取2000-2015年全球40支股票指数日收盘价, 建立收益率网络和DCC-MVGARCH模型波动率网络对中 国股票市场国际联动性进行实证分析。其研究表明, 全球 股市收益率和波动率联动逐渐增强; 全球金融危机和欧债 危机期间, 收益率联动网络具有小世界性, 中国与全球股 市长期处于割裂状态; 但在全球金融危机期间与其他市场 联系加强。

虽然近期的研究大部分均表明中国股市与外围市场联 动日趋紧密, 但是随着欧美国家逐渐从危机中走出来, 在美 国道琼斯指数再创历史新高的同时, 中国的股市却还在 2000-3000点附近徘徊, 只是前期高点的二分之一左右, 难 道中国的股市依然独立于世界主要股票市场吗? 本文采用 2006年1月4日至2016年4月28日的数据来进行实证研究, 以 期考察中国股市的发展与主要股市关系发生了怎样的变化。

\section{3. 路径分析}

关于国际股票市场联动的路径分析, 大致可以分为三 类：一类是经济基础假说，该假说假设投资者完全理性， 
资产基本面是资产价格联动的起因; 由于世界各国存在共 同影响其经济的变量, 各个经济体间经济以及金融联系导 致股票市场存在联动性。Gerrits\&Yuce[16]认为, 全球经 济贸易的高速增长，商品、服务、金融资产以及人力资本 等要素流动及各国政府合作的增加均使全球金融市场之 间的联动越发紧密。Adler\&Dumas[17]认为某国的宏观经 济变动会影响跨国套利投资者的投资决策, 从而改变投资 资产组合, 其他国家的股票价格会及时对该类信息作出反 应, 从而证明股市相关性根源于经济基本面之间的联系。 Contessi等[18]的研究结果表明, 由于欧元的出现以及欧洲 各个国家的经济结构趋同显著增强了欧洲各国股市之间 的联动效应。另一类路径分析为市场传染假说, 该假说重 视金融市场所特有的行为特征以及投资者的行为, 认为当 一个国家的股票市场受到负面消息的冲击而产生负面影 响, 各个市场上投资者的行为会对其他国家产生严重影响, 从而导致国家间股市联动。Connolly\&Wang[19]的研究表 明，一些投资者会从股票收益率中等可观察的信息，并在 此基础上调整他们的投资组合, 最终会引起不同股市收益 率之间的相关性。此外, 股市联动性与政府政策紧密关联, 即股市联动性的第三个传导路径一政策冲击假说,

Bekaert\&Harvey[20]认为任何促进国家间经济金融互动的 政府政策均会对国际股市联动性产生正向冲击。经济开放 度的提升，市场利率化和汇制改革、金融深化和量化宽松 的货币政策均会影响国际股票市场间的联动性。国内对于 股市联动的路径分析则主要侧重于中国和外围市场相互 间产生联动的原因分析。游家兴和郑挺国[21]指出, 我国 与外围市场的联动性愈发紧密的原因在于中国金融自由 化政策的逐步推进和深化, 我国证券市场才得以从最初相 对外界绝缘的分割状态逐渐走向与发达市场接轨。

基于上述股市联动的理论分析，结合国际贸易量和金融 深化改革的不断提升, 以及我国资本市场对外不断开放的事 实，本文假设中国股市与主要股票市场的联系越来越密切。

\section{4. 实证研究结果及分析}

\section{1. 样本选择与数据分析}

本文主要选取以下股票指数作为考察对象：上证综指 (用SHZ来表示)、深证成分指数(SZC)、恒生指数(HSI)、道 琼斯工业指数(DQS)和日经225指数(RJI)。选取道琼斯工业 指数、日经指数作为样本数据, 主要是因为美国和日本均 是世界重要的前三大经济体, 其股市在各国经济中都有着 重要作用, 股票种类多, 市场规模大, 交易制度比较完善, 股票市场能够较好地反映当地的经济发展状; 恒生指数则 由于其特殊的地理位置及政治地位，对内地股市也具有一 定的影响; 而深证成分指数作为中国重要的股票指数之一, 且与上证综指处于基本相同的宏观环境下，与上证综指有 重要的关联性。

对五个样本指数取对数处理, 分别用LSHZ、LSZC、 LHSI、LDQS、LRJI来表示, 对取对数之后的指数进行一 阶差分处理, 分别用DLSHZ、DLSZC、DLHSI、DLDQS、 DLRJI表示。将考察的样本时间段定为2006年初至2016年4 月28日, 因为不同国家(地区)的法定节假日不同, 以及受突 发事件的影响等，所以不同股票市场的交易时间之间存在 着一定的差异。本文将从样本中剔除部分数据, 每个指数 均只保留相同交易日的数据, 经处理后, 每个股票指数序 列共 2246 个数据样本。本文所用的数据均来自wind数据库。

\section{2. 平稳性检验}

因为选取的股票指数数据都是时间序列数据, 首先进 行平稳性检验并确定各时间序列的单整阶数。在进行单位 根检验之前可以先参考样本所选指数日收盘价线性图, 可 以根据图中各股票指数走势对他们之间的关系有个总体 上的判断。图1为样本指数2006年1月4日至2016年4月 28 日的收盘价线形图。

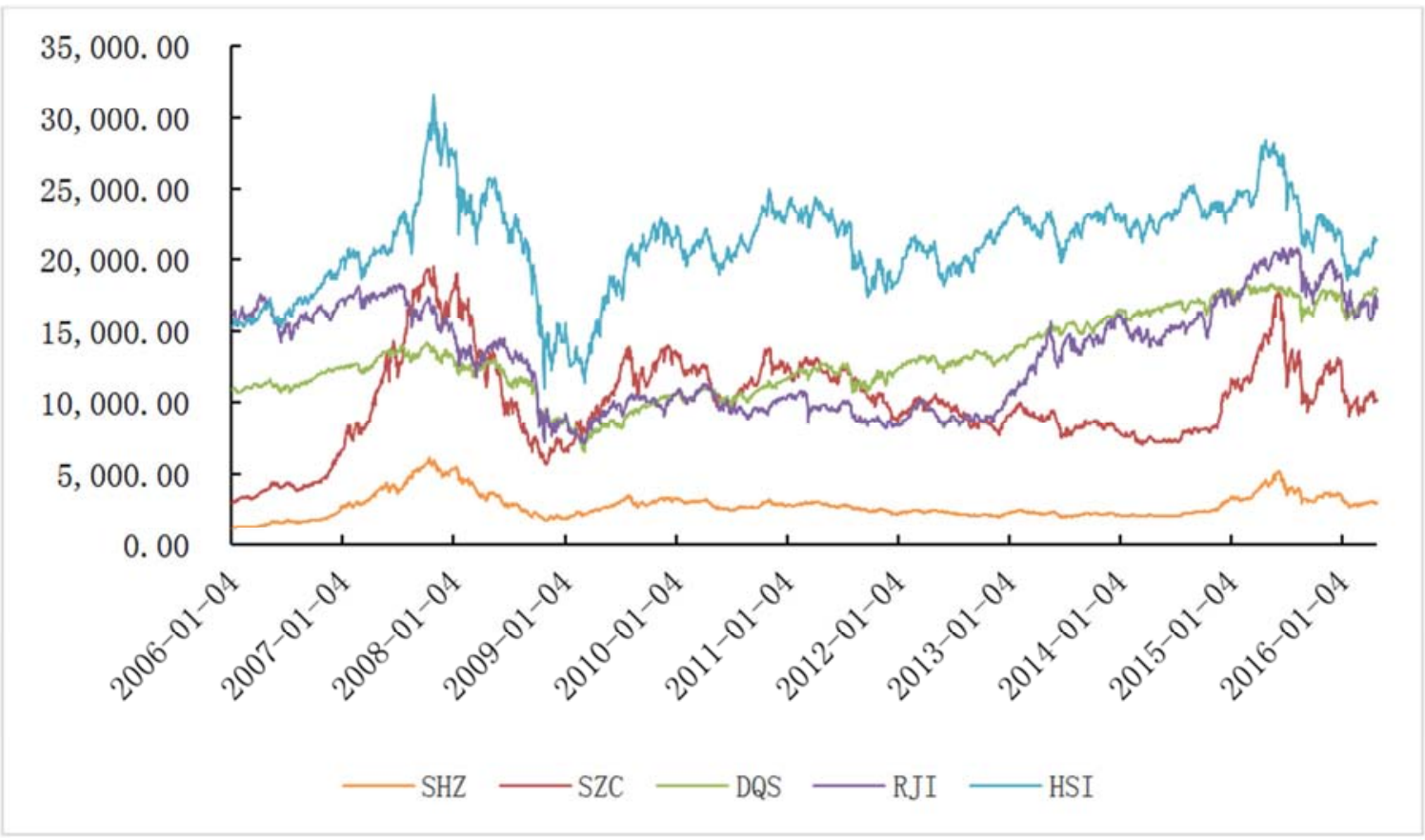

图1 2006-1-4至2015-4-28主要股指日收盘价线形图。 
从图1可以看出样本所选指数的波动趋势在某些时间 段走势大体相似, 尤其是在2007年美国次贷危机之后至 2010年间, 深圳成指、香港恒生指数以及日经 225 指数之 间的波动趋势一致性较为明显, 而上证综指大体趋势一致, 变动相对比较平稳。但是2011年之后的各股指走势有发生 可一定地差异, 道琼斯和日经 225 指数均开始上行, 深圳 成指下行盘整, 恒生指数也在一定区间内震荡, 上证综指 变动较为平稳调整, 在 2015 年之后总体趋势又大体相同。 从样本的走势也可以看出, 样本初始序列是非平稳序列, 需要进行相关的处理。因此我们对样本序列进行了取对数 和差分处理, 这样一方面可以增强序列的平稳性, 另一方 面也可以使变量的经济意义更加显著, 取对数差分的序列 即DL，表示股指的收益率序列。 见表1。

对样本处理后各股票指数序列进行单位根检验, 结果

表1 各变量的平稳性检验结果。

\begin{tabular}{lllll}
\hline 变量 & ADF值 & 临界值(1\%) & P值 & 平稳性 \\
\hline LSHZ & 0.8838 & -2.5660 & 0.8993 & 不平稳 \\
DLSHZ & -47.9772 & -3.4331 & 0.0001 & 平稳 \\
LSZC & 1.0491 & -2.5660 & 0.9235 & 不平稳 \\
DLSZC & -46.3986 & -3.4331 & 0.0001 & 平稳 \\
LHSI & 0.361796 & -2.5660 & 0.7891 & 不平稳 \\
\hline
\end{tabular}

\begin{tabular}{lllll}
\hline 变量 & ADF值 & 临界值(1\%) & P值 & 平稳性 \\
\hline DLHSI & -50.2115 & -3.4331 & 0.0001 & 平稳 \\
LRJI & -0.0210 & -2.5660 & 0.6757 & 不稳 \\
DLRJI & -49.1026 & -3.4331 & 0.0001 & 平稳 \\
LDQS & 0.8580 & -2.5660 & 0.8951 & 不稳 \\
DLDQS & -51.0218 & -3.4331 & 0.0001 & 平稳 \\
\hline
\end{tabular}

由上表可知, 指数序列查分前的平稳性检验显示, 各 指数对数序列的 $\mathrm{ADF}$ 值均大于 $1 \%$ 的临界值, $\mathrm{P}$ 值均大于 0.05 , 所以应接受原假设, 即各对数序列为非平稳序列。 而进行一阶差分后, 对数序列的 $\mathrm{ADF}$ 值均小于 $1 \%$ 的临界 值, $\mathrm{P}$ 值小于 0.05 , 因此拒绝原假设, 即认为一阶差分后 的时间序列为平稳性时间序列, 且所有时间序列都是一阶 单整, 满足协整检验的前提。

\section{3. 协整分析}

由平稳性分析可知, 本文所采用的时间序列, 全部为 一阶单整序列, 因此可以进行协整分析。为了将上证综指 分别与其他主要股指的关系进行协整分析, 先将LSHZ与 LSZC、LHSI、LRJI、LDQS采取普通最小二乘法进行回 归分析, 建立回归分析, 建立回归方程, 结果如下:

$\mathrm{LSHZ}=-0.1902+0.7870 \mathrm{LSZC}+0.0941 \mathrm{LHSI}+0.0109 \mathrm{LRJI}-0.0214 \mathrm{LDQS}+[\mathrm{AR}(1)=0.9982]+\hat{u} t$

$\begin{array}{lll}(-1.23) \quad(104.30) & (7.6887)(0.98)(-1.76)(848.79)\end{array}$

$$
\overline{R^{2}}=0.99 \quad \text { D.W. }=1.9138 \quad \mathrm{~F}=846140.4
$$

在回归方程中加入了 AR(1)项, 是为了消除自相关性, 方程的拟合优度达到 0.99 , 拟合效果较好, 且LSZC,LHSI 系数的 $t$ 值检验在 0.01 置信水平下显著, LDQS系数的 $t$ 值检 验在 0.1 置信水平下显著, 而LRJI系数的 $\mathrm{t}$ 值检验在 0.5 的置 信水平下检验显著。

对方程的残差项进行平稳性检验，检验结果如表2如 下:

表2 残差项ECM单位根检验表。

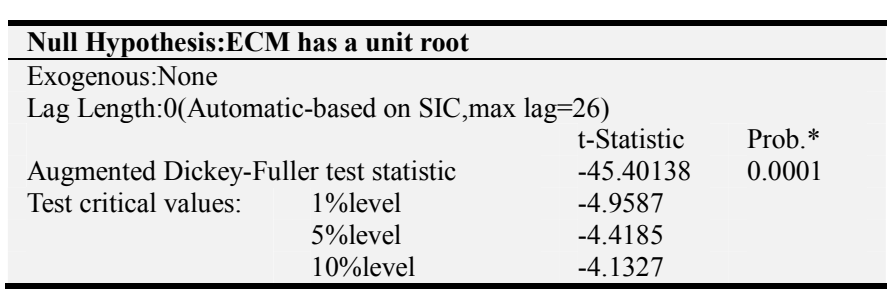

*Mac Kinnon(1991)one-sided p-values.

从上表的检验结果可以看出, 协整方程的残差序列的 $\mathrm{ADF}$ 值为 -45.40 , 明显小于 0.01 置信水平下的临界值 -4.9587 , 因此拒绝存在单位根的假定, 表明残差项是稳定 的。据此可以判断LSH、Z与LSZC、LHSI、LRJI、LDQS 的协整关系是存在的, 变量间存在长期稳定的均衡关系。
方程的拟合效果及残差如图2所示:

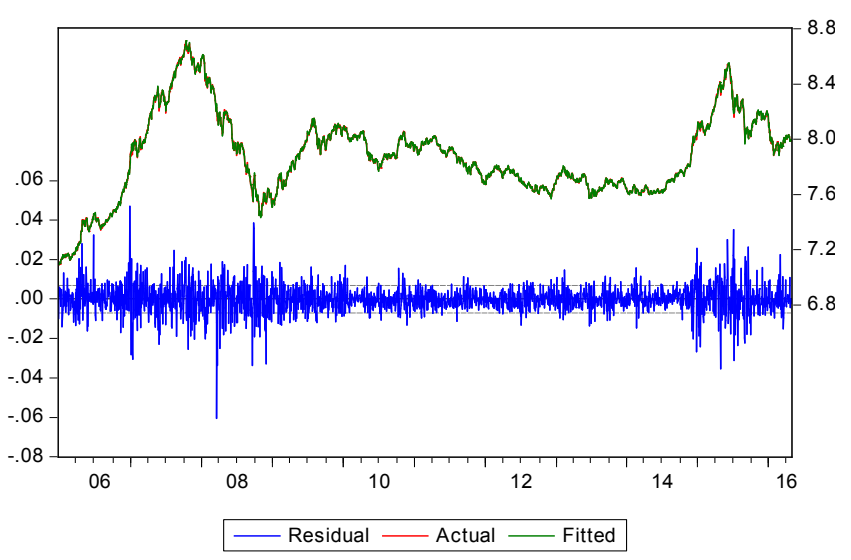

图2 方程的拟合效果及残差图。

\subsection{Granger因果检验}

根据AIC准则, 当各变量的滞后阶数为 4 时, 能够更好 地描述这四个变量序列, 所以在Granger因果关系检验中, 我们选定滞后阶数为 4 . 对变量的对数序列和收益率分别 进行Granger因果关系进行检验, 结果如表4、表5所示 
表3 对数序列Granger因果检验结果。

\begin{tabular}{llll}
\hline Null Hypothesis: & Obs & F-Statistic & Prob. \\
\hline LSZC does not Granger Cause LSHZ & 2242 & 2.50607 & 0.0403 \\
LSHZ does not Granger Cause LSZC & & 2.41118 & 0.0472 \\
LHSI does not Granger Cause LSHZ & 2242 & 1.22184 & 0.2994 \\
LSHZ does not Granger Cause LHSI & & 4.20091 & 0.0022 \\
LRJI does not Granger Cause LSHZ & 2242 & 0.87545 & 0.4778 \\
LSHZ does not Granger Cause LRJI & & 0.69310 & 0.5967 \\
LDQS does not Granger Cause LSHZ & 2242 & 17.3916 & $5 . E-14$ \\
LSHZ does not Granger Cause LDQS & & 0.23398 & 0.9193 \\
\hline
\end{tabular}

表4 收益率序列Granger因果检验结果。

\begin{tabular}{llll}
\hline Null Hypothesis: & Obs & F-Statistic & Prob. \\
\hline DLSZC does no Granger Cause DLSHZ & 2241 & 1.44686 & 0.2160 \\
DLSHZ does not Granger Cause DLSZC & & 2.52997 & 0.0388 \\
DLRJI does not Granger Cause DLSHZ & 2241 & 0.14314 & 0.9660 \\
DLSHZ does not Granger Cause DLRJI & & 0.45324 & 0.7701 \\
DLHSI does not Granger Cause DLSHZ & 2241 & 1.18265 & 0.3164 \\
DLSHZ does not Granger Cause DLHSI & & 3.55036 & 0.0068 \\
DLDQS does not Granger Cause DLSHZ & 2241 & 18.0839 & $1 . E-14$ \\
DLSHZ does not Granger Cause DLDQS & & 2.34856 & 0.0523 \\
\hline
\end{tabular}

从表 3 可以看出, 上证综指与深圳成指均在 0.05 置信 水平下, 成双向Granger原因, 日经 225 指数与上证综指互
不为Granger原因。而上证综指是恒生指数的Granger原因, 恒生指数不是上证综指的Granger原因, 一定程度上说明 中国内地股票市场对香港股票市场的影响较大, 道琼斯工 业指数是上证综指的Granger原因。

从表4显示收益率序列的Granger因果检验结果, 上证 综指是深圳成指、恒生指数的Granger原因, 反之不成立。 道琼斯工业指数是上证综指的Granger原因。综合表 $3 、$ 表 4的结果我们发现, 我们的股市对外围股市的影响较大, 但是其自身走势却有一定的内在性, 受外围股市的影响较 小, 在所选择的样本中, 只有道琼斯指数对上证综指的影 响通过了系数检验。

\section{5. 误差修正模型}

上述协整检验部分，论述了上证综指、深圳成指、恒 生指数、日经 225 指数、道琼斯工业指数的对数序列呈现 协整关系, 由Granger表述定理可知, 我们可以建立他们 的误差修正模型。我们以协整关系是的残差序列一阶滞后 项作为误差修正项, 能够建立以下误差修正模型。

\section{$\mathrm{DLSHZ}=-2.66 \mathrm{E}-05+0.7884 \mathrm{DLSZC}+0.0927 \mathrm{DLHSI}+0.0110 \mathrm{DLRJI}-0.0228 \mathrm{DLDQS}$}

$$
(-0.18)(104.48)(7.54)(1.00)(-1.88)
$$

$$
-0.0123 \mathrm{DLSHZ}(-1)+0.0534 \mathrm{ECM}(-1)
$$

$$
\overline{R^{2}}=0.87 \text { D.W. }=1.9963
$$

综合(1) (2) 式, 我们可以发现, 不论长期还是短期, 上证综指与深证成指、恒生指数、日经 225 指数均是正相 关，而与道琼斯工业指数则成负相关。其中深证成指的影 响最为显著, 大于恒生指数、日经 225 指数、道琼斯工业 指数对上证综指的影响。长期来看, 上证综指关于深证成 指、恒生指数、日经225指数、道琼斯工业指数的弹性分 别为 $0.787 、 0.0941 、 0.0109 、-0.0214$ 。误差修正模型式则 表明上证综指关于深证成指、恒生指数、日经225指数、 道琼斯工业指数的弹性分别为 $0.7884 、 0.0927 、 0.0110$ 、 -0.0228、0.0123。根据误差修正项的系数估计值来看, 当 短期波动偏离长期均衡时, 将以0.0534的调整力度, 将非 均衡状态回调至均衡状态。

\section{6. 脉冲响应分析}

脉冲响应函数用于衡量模型受到某种冲击时对系统 的动态影响, 能够比较地观地刻画出变量之间的动态交互 作用及其效应。

\subsection{1. 上证综指对深证成指的脉冲响应}

从上证综指对深证成指的脉冲响应图3来看, 给上证综 指一个单位的正向冲击, 会首先产生降低深证成指的作用。 但下降只会持续3交易日左右的时间，随后上升，大约持续 1 个交易日的时间，深证成指对上证综指的冲击便会消失。

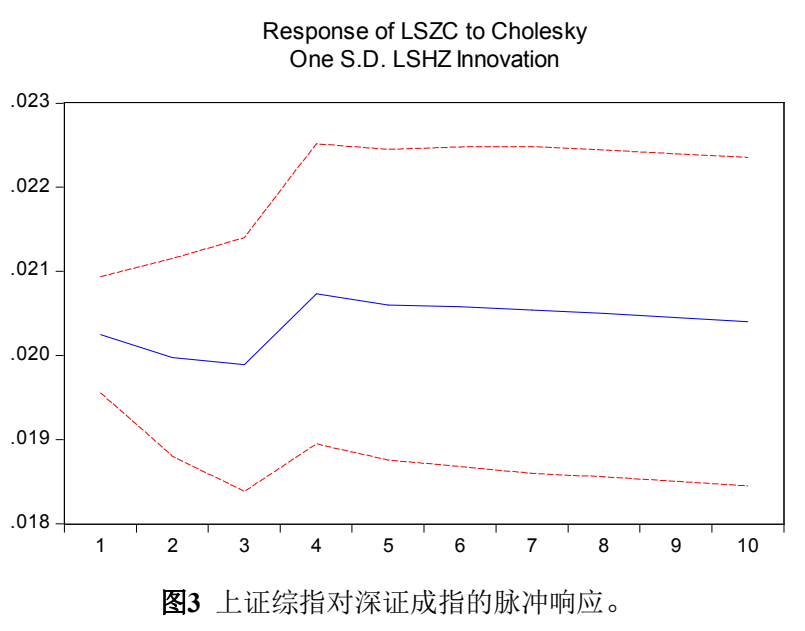

\subsection{2. 上证综指对恒生指数的脉冲响应}

从上证综指对恒生指数的脉冲响应图4来看, 给上证 综指一个单位的正向冲击, 恒生指数大幅下降, , 但下降 之会持续1交易日左右的时间。随后恒生会微幅上调, 并 在1交易日后又做下调。在第 4 个交易日之后, 深证成指对 上证综指的冲击便会消失。

\section{6. 3. 深证成指对上证综指的脉冲响应}

从深证成指对上证综指的脉冲响应图5来看, 给深证 成指一个单位的正向冲击, 会首先产生提高上证综指的作 用，持续时间仅为 1 交易日，上证综指价格在相对较高的 
价格平稳下来。但在第 3 交易日时间里, 上证指数继续上 调, 随后深证成指对其冲击的影响便会消失。

\section{6. 4. 道琼斯指数对上证综指的脉冲响应}

从道琼斯指数对上证综指的脉冲响应图6来看, 给道琼 斯指数一个单位的正向冲击, 上证综指大幅上扬, 但仅持续 一个交易日。随后，深证成指对上证综指的冲击便会消失。

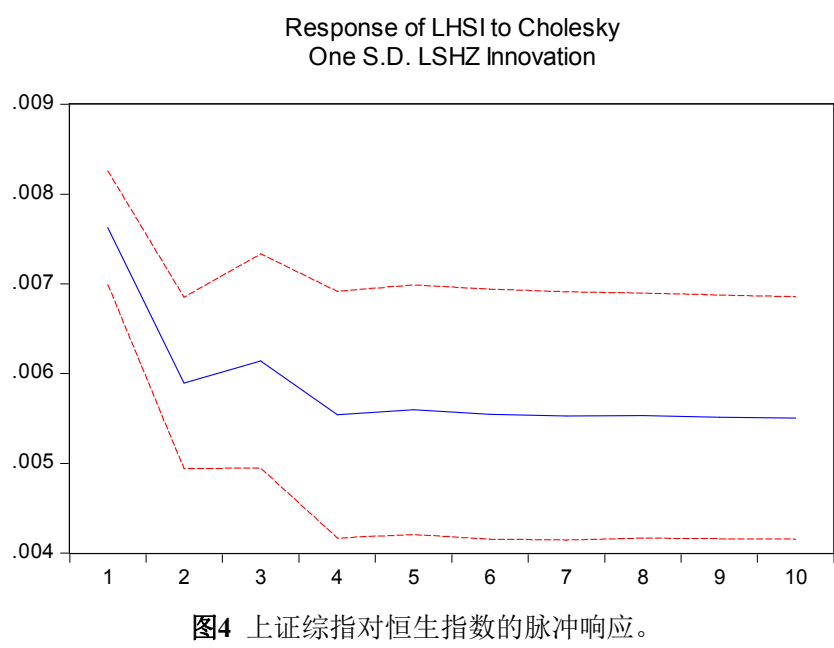

Response of LSHZ to Cholesky One S.D. LSZC Innovation

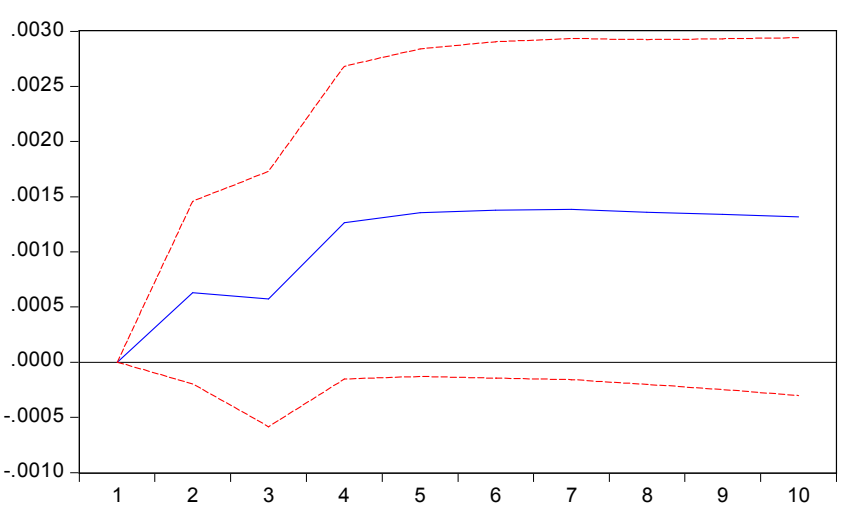

图5 深证成指对上证综指的脉冲响应。

Response of LSHZ to Cholesky One S.D. LDQS Innovation

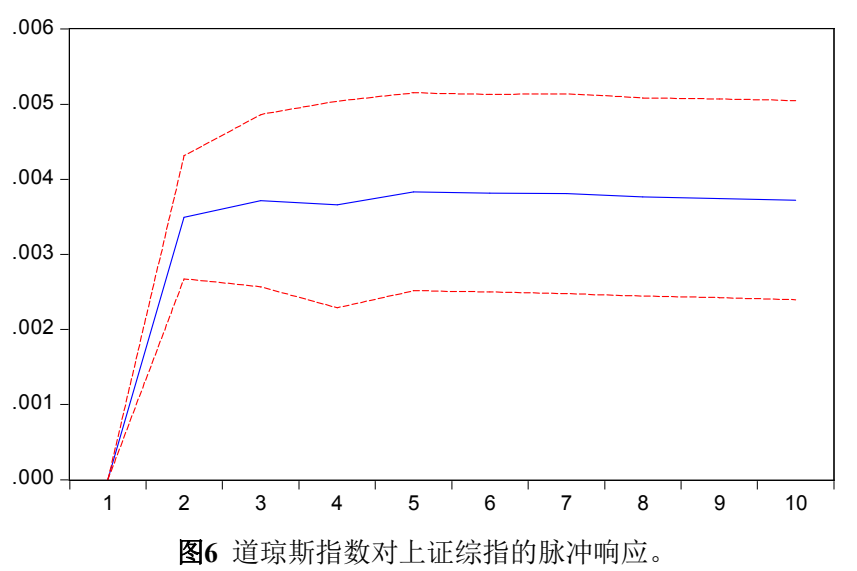

\section{5. 结论}

本文以2006年1月4日至2016年4月28日的上证综指以 及深证成指、恒生指数、日经 225 指数、道琼斯工业指数 为样本, 使用协整、Granger因果关系检验等方法对中国 股票市场与其他股票市场之间的关系进行了实证研究。

研究结果表明, 从长期来看, 上证综指与深证成指、 恒生指数、日经 225 指数、道琼斯工业指数存在一个均衡 关系的, 表明随着我国金融市场改革措施的不断推进，中 国股市已经开始融入国际股票市场。在四个样本中，深证 成指与上证综指的关系最为紧密。其次为恒生指数, 这与 香港作为亚洲金融中心, 地理位置接近珠三角的现实情况 相符。误差修正模型方程的拟合优度还可以且Granger因 果检验也显示, 外围股票市场对上证综指的影响有限, 这 也说明了中国股市的走势还是具有很强的内生性。

研究结果还表明, 上证综指为深证成指、恒生指数的 Granger原因，然而对于其他外围市场的影响并不明显。 中国的资本市场有待进一步发展与完善, 以增加对外围市 场的影响。

\section{参考文献}

[1] Jin Gil Jeong. Cross-border Transmission of Stock Price Volatility: Evidence from the Overlapping Trading Hours [J]. Global Finance Journal, 1999 (1): 53-70.

[2] 俞世典, 陈守东. $\mathrm{Z}$ 主要股票指数的联动分析 $[\mathrm{J}]$. 统计研 究, 2001(8): 42-46。

[3] 陈守东, 韩广哲, 荆伟. 主要股票市场指数与我国股票市 场指数间的协整分析 $[\mathrm{J}]$. 数量经济技术经济研, 2003(5): 124-129。

[4] 韩非, 肖辉. 中美股市间的联动性分析 [J]. 金融研究, 2005(11):117-129。

[5] 倪振州, 吉余锋. 次贷危机前后中美股市波动溢出效应研 究[J]．中国市场，2010(31): 45-47。

[6] 刘琬婷, 朱羽. 中国股市与世界主要股票市场联动性的实 证研究[J]. 金融经济, 2008(16): 98-100。

[7] 陈漓高, 吴鹏飞, 刘宁. 国际证券市场联动程度的实证分 析. 数量经济与技术经济研究 $[\mathrm{J}], 2006(11): 124-132$ 。

[8] 秦伟广，杨瑞成. 我国股票市场指数与国际股票市场主要 指数的联动性研究 $[J]$. 技术经济, 2010(11): 103-109。

[9] 胡秋灵, 刘伟. 中美股市联动性分析-基于次贷危机背景下 的收益率研究 [J]. 证券市场, 2009(6)期：79-84。

[10] 张兵, 范致镇, 李心丹. 中美股票市场的联动性研究 [J]. 经 济研究, 2010(11): 141-151。

[11] 王一帆,武俊伟,刘斌.关于中美股票市场联动关系的实证研 究[J].中国证券期货，2011(7): 28-29。 
[12] 裴延华,余万林.基于沪港通前后沪港和沪美股市联动性的 比较分析[J]. 武汉金融, 2017(4): 26-29。

[13] 王杰, 王帅. 中美股市联动性分析 [J]. 中国证券期货, 2012(11): 17-20。

[14] 郑德珵, 孙路，陈哲. 全球金融危机前后境内外股票市场 联动性实证分析 $[\mathrm{J}]$. 产经评论, 2013(6): 128-139。

[15] 李岸, 粟亚亚, 乔海曙. 中国股票市场国际联动性研究一 基于网络分析方法 $[\mathrm{J}]$. 数量经济技术经济研究, 2016(8): 113-127。

[16] Gerrits, R. J., A.Yuce.Short-and-Long-term Links among European and U. S. Stock Markets [J]. Applied Financial Economics, 1999, 9 (1): 1-9.
[17] Adler M,B.Dumas.The International Portfolio Choice and Corporate Finance [J]. Journal of Finance, 1983 (38): 925-984.

[18] Contessi, S., P. De Pace and J.Francis.The Cyclical Properties of Disaggregated Capital Flows [J]. Journal of International Money and Finance, 2013 (32): 528-555.

[19] Connolly, R. A. and F.A.Wang.On Stock Market Return Co-movements: Macro economic News,Dispersion of Beliefs, and Contagion [J]. SSRN, 2002, http:ssrn.Com abstract $=233924$.

[20] G Bekaert, CR Harvey.Time-Varying World Market Integration [J]. Journal of Finance, 1994, 50 (2): 403-444.

[21] 游家兴, 陈珍珍, 郑挺国. 经济一体化与证券市场联动性 一基于相关经验数据的分析 $[\mathrm{J}]$. 厦门大学学报(哲学社会科 学版), 2010(2): 21-28。 